\title{
Global Scientific Vision With Local Vigilance: Renal Transplantation in Developing Countries
}

\author{
Mohammad Reza Ardalan ${ }^{1, *}$ \\ ${ }^{1}$ Chronic Kidney Disease Research Center, Tabriz University of Medical Sciences, Tabriz, IR Iran \\ ${ }^{*}$ Corresponding author: Mohammad Reza Ardalan, Chronic Kidney Disease Research Center, Tabriz University of Medical Sciences, Tabriz, IR Iran. Tel: +98-9141168518, Fax: +98- \\ 4113366579, E-mail: ardalan34@yahoo.com
}

Received: August 9, 2014; Revised: August 30, 2014; Accepted: September 13, 2014

\begin{abstract}
Context: Renal Transplantation is the most effective treatment for patients with end-stage renal disease, which is fortunately available in the developing countries, even for poor people. Nonetheless, the way forward should be the implementation of advanced science of transplantation, allograft monitoring abilities, knowledge about the epidemiology of renal disease in any specific region, awareness about the influence of ethenic and genetic factors immunosuppressant bioavailability, and post-transplant complications all strongly affecting the patients and allograft survival.

EvidenceAcquisitions: In this process we searched mainly in PubMed, Web of Science and Google Scholar data bases for key words of renal allograft monitoring, post-transplant infections, renal/kidney transplantation and Iran. We followed the cross articles to follow our main idea to find a connection between modern advancement in renal allograft monitoring and our practice in developing countries. Another focus was on the special infectious and non-infection complication that do exist in specific region and need specific considerations.

Results: Implementation of modern techniques of immune monitoring, allograft function, awareness about the specific infectious and non-infectious disease in each region improves the quality of renal transplantation.

Conclusions: We need to combine the advance scientific vision with local vigilance to achieve the best outcome in renal allograft recipients
\end{abstract}

Keywords:Transplantation; Tissue Donors; Antibodies; MicroRNAs

\section{Context}

Renal transplantation is the most effective treatment for patients with end-stage renal disease. Fortunately, this treatment is available, even for poor people, in developing countries (1); in these countries, however, the way forward should be increasing the quality and expanding the knowledge of transplantation medicine and implementation of advanced technology of allograft monitoring rather than increasing the centers. Better understanding of the epidemiology of renal disease will lead to better management and outcome. Emerging epidemic of diabetes and hypertension are expanding very fast in the Middle East; moreover, special genetic, infectious, and immunologic factors do exist in certain region that need special consideration $(1,2)$. Some ethnic groups are at increased risk of immunosuppressant complications; therapeutic index for immunosuppressive medicines is narrow and should be in a fine balanced to avoid underdosing or overdosing. In renal transplant recipients, unusual infections are common and might have an unusual pictures. Infections complications not only depend on the state of immunosuppression, but also on the genetic background of the patients $(3,4)$.

\section{Evidence Acquisitions}

In this process we searched mainly in PubMed, Web of
Science and Google Scholar data bases for key words of renal allograft monitoring, post-transplant infections, renal/kidney transplantation and Iran. we followed the cross articles to follow our main idea to find a connection between modern advancement in renal allograft monitoring and our practice in developing countries. Another focus was on the special infectious and non-infection complication that do exist in specific region and need specific considerations.

\section{Results}

\subsection{Primary Renal Disease and Genetic Factors}

It is very important to have enough knowledge about the underlying renal disease. Early recurrence of mild IgA nephropathy (IgAN) happens in up to $32 \%$ of patients within the first year of transplantation; nevertheless, most of the time it is mild and does not associate with lower clinical outcome (5). The phospholipase A2 receptor (PLA2R) antibody is a good marker of primary membranous nephropathy (MN) and its activity and recurrence after transplantation (6). A higher recurrence rate of MN has been observed in recipients of living related donor than in recipients of living unrelated donors. The

Copyright (C) 2015, Nephrology and Urology Research Center. This is an open-access article distributed under the terms of the Creative Commons Attribution-NonCommercial 4.0 International License (http://creativecommons.org/licenses/by-nc/4.0/) which permits copy and redistribute the material just in noncommercial usages, provided the original work is properly cited. 
role of genetic factors in higher recurrence such as HLA$D Q A 1$ allele should be studied in different populations (7).

Systemic Lupus erythematosis (SLE) needs special considerations although there are good outcome in SLE patients who have received kidney from living donors (8). Multiple myeloma (MM) is an important cause of renal failure and often presents in various and confusing features. Missing the underlying MM could be a great mistake, particularly when patient is planned for preemptive renal transplantation $(9,10)$. Combined kidney and bone marrow transplantation without immunosuppression has been reported as a successful modality for patient with MM and renal failure (10). Primary focal segmental glomerulosclerosis (FSGS) often recurs immediately after transplantation. Genetic study of the patients and searching for circulatory permeability factors such as soluble urokinase-type plasminogen activator receptor (SUPAR) are important to understand the underlying pathophysiology and monitoring the recurrence of FSGS $(11,12)$. It has been reported that the type of dialysis modality does not affect the patient and graft outcome (13, 14); however, hepatitis viruses transmission is higher in patients on hemodialysis while peritoneal dialysis has its own special complications $(15,16)$. Despite the good result of transplantation in aged population, increased risk of infection and hidden comorbid conditions should be considered in them (17).

\subsection{Watching the Allograft}

Intrarenal hemodynamic monitoring of the allograft and measurement resistive index are useful and noninvasive methods of monitoring and each transplant center should expand its experiences; moreover, a close cooperation between clinicians and radiologists is needed (18, 19). MicroRNAs (miRNAs) are powerful regulators of gene transcription. Tubular epithelial cells robustly upregulate microRNA 21 (mir21) after renal ischemia (20). Chronic allograft nephropathy is the most common cause of kidney allograft loss and even with the implementation of recent immunosuppressant, the picture has not altered. Serum creatinine and glomerular filtration rate (GFR) have limited roles in estimating the histopathologic changes. Recent progress in the area of microRNA has hold a great promise to identify the renal fibrosis (21, 22). In addition, miR-142-5p is a promising biomarker for long-term renal allograft monitoring (22).

The HLA antibody tests are subdivided into cell-based and solid-phase tests. Cell-based tests include complement-dependent lymphocytotoxity (CDC) and flow cytometric cross-match. Solid-phase tests include enzymelinked immunosorbent assays (ELISAs) and multi-analyte bead tests either by flow cytometry or Luminex technology (23). Circulating donor-specific antibodies (DSA) against HLA class I or II have deleterious effect on the graft, and. Anti-class II DSAs promotes chronic rejection (24). Measuring the C1q-binding capacity of anti-HLA DSA with the use of single-antigen flow bead assay determines its complement fixing capacity and its graft damaging capacity. C1q testing could identify at-risk patients who are C4d negative during the immunohistologic study of renal allograft (25). A dose-response curve does exist between DSA levels and intra-graft C4d deposition (26).

Luminex cross-matching is a powerful measurement for detection of DSA against HLA class I. With mean fluorescence intensity (MFI) $\geq 900$, Luminex cross-matching gives the best prediction of antibody-mediated rejections (AMR) (sensitivity of $75 \%$ and specificity of $90 \%$ ) (27, 28). Pretransplant DSA could tailor the intensity of immunosuppression in sensitized patients (29). Increase of DSA one week after transplantation is a risk factors for rejection in sensitized patients and MFI $>3000$ is in favor of future allograft C4d deposition (30). High risk patients benefit from antibody-depleting therapies and DSA monitoring, even beyond the first year of transplantation (24).

\subsection{Special Posttransplant Events}

Posttransplantation malignancies are important complication and are influenced by the degree of immunosuppression, viral infections, and recipient age. Squamous cell carcinoma of the skin is the most common malignancy and affected patients have a five-fold increased risk of developing another solid tumor (31). In European population, posttransplant lymphoproliferative disorders (PTLD) are the second most common malignancies and the same features were founded in a report from Iran (32-34). Geographic distribution of human herpes virus type-8 and Epstein-Bar virus (EBV) infections are important risk factors for Kaposi sarcoma and PTLD development, respectively $(33,34)$.

Genetic factors affect the susceptibility of insulin secretion capacity in pancreatic islets cells and its inhibition by calcineurin inhibitors (CNI) and hence, development of new-onset diabetes after transplantation (NODAT) (35, 36). Metformin has protective roles on the development of $\operatorname{NODAT}(35,36)$. Posttransplant thrombotic microangiopathy is an important and confusing condition, which manifests with anemia thrombocytopenia and renal dysfunction, and transplant physician should be familiar with its unusual features (37-39). Hyperparathyroidism and its adverse effects could be continued after renal transplantation (40).

\subsection{Specific Post Transplant Infections}

BK virus (BKV) nephropathy continues to be a major concern. It develops after viruria and viremia phases. Urinary decoy cell surveillance using a cutoff of $>10$ cells/ hpf is a useful screening strategy (41). Tacrolimus increases the risk of BK infection; BKV-specific T-cell immunity and natural-killer cell receptor genotype are predictors of immune response to BKV and therapeutic outcome (42). Cytomegalovirus (CMV) is the most important viral 
infection after renal transplantation and presents with different pictures (43-45). Inadequate treatment of CMV leads to emergence of resistance strains $(46,47)$. Majority of organ donors and recipients in developing countries are seropositive for anti-CMV IgG antibody ( $\mathrm{D}+/ \mathrm{R}+)$, but even in this group, there are $49 \%$ chance of developing viremia $(46,47)$. Late-onset CMV affects the allograft two years after transplantation and predisposes the allograft to intense interstitial fibrosis $(46,47)$. Parvovirus B19 has special feature in renal transplant recipients and could be present as a combination of allograft dysfunction with pancytopenia $(48,49)$. Bacterial infection of the renal allograft could happen during the early periods of transplantation (50). Aspergillosis is a fatal infection and easily expands, particularly during the maximum immunosuppression (51). Mycobacterial infection is very common in developing countries where there are active transplantation program. Transplantation could exacerbate the course of leprosy and should be considered when there are suspicious skin lesions, particularly in endemic areas $(52,53)$.

\section{Conclusions}

Viral hemorrhagic fever infections (VHF) do exist in Middle East region and Iran. Arboviral hemorrhagic fever should be considered in the differential diagnosis of aseptic meningitis and encephalitis. Prevention of arboviral disease depends on community and household efforts to reduce mosquito densities (54-56). In addition, hemorrhagic fever with renal syndromes (HFRS) is responsible for renal dysfunction in the endemic region and can affect the native or allograft kidneys (56). Bacterial infection-associated glomerulonephritis needs special consideration in Middle East region. Brucellosis and periodontal diseases could be the underlying cause of active glomerulonephritis and renal allograft involvement $(57,58)$. Renal involvement of familial Mediterranean fever (FMF) and Behçet's disease needs specific consideration in the Middle East region, particularly in Turkish-Azeri ancestries. Patients with FMF who lost their allograft should continue their anti-inflammatory therapy even after renal transplantation. FMF-induced fever attacks and serum creatinine elevation could happen after transplantation and misdiagnosed as a systemic microbial infection (59-61). Gelsolin amyloidosis is a rare cause of familial amyloidosis and renal failure. Facial nerve paresis and skin involvement in the form of cutis laxa are its specific features and are reported from Middle East region. In gelsolin amyloidosis, renal outcome is excellent after transplantation $(62,63))$. Traditional herbal medicine are prevalent in developing country and they are often considered natural and safe while some of them are potentially nephrotoxic and impose risk on both native and allograft kidneys (64). We need to combine the global scientific vision with our local vigilance to deliver the utmost help to our renal transplant recipients.

\section{References}

1. Ebpg Expert Group on Renal Transplantation . European best practice guidelines for renal transplantation. Section IV: Longterm management of the transplant recipient. Nephrol Dial Transplant. 2002;17 Suppl 4:1-67.

2. Jacob AA. Guillermo Garcia Garcia Paul Harden, Jeremy Chapman The Global Role of Kidney Transplantation. Nephrol Dial Transplant. 2012;1(1).

3. Gonzalez A, Schmitter K, Hirsch HH, Garzoni C, van Delden C, Boggian K, et al. KIR-associated protection from CMV replication requires pre-existing immunity: a prospective study in solid organ transplant recipients. Genes Immun. 2014;15(7):495-9.

4. Ardalan MR. Tabriz nephro-educational courses; A global scientific vision with local vigilance. J Ren Inj Prev. 2014;3(1):7-8.

5. Ortiz F, Gelpi R, Koskinen P, Manonelles A, Raisanen-Sokolowski A, Carrera M, et al. IgA nephropathy recurs early in the graft when assessed by protocol biopsy. Nephrol Dial Transplant. 2012;27(6):2553-8.

6. Ardalan MR, Nasri H. Anti-phospholipase A2 receptor antibody in idiopathic membranous nephropathy: New concepts. J Res Med Sci. 2013;18(6):459-61.

7. Stanescu HC, Arcos-Burgos M, Medlar A, Bockenhauer D, Kottgen A, Dragomirescu L, et al. Risk HLA-DQA1 and PLA(2)R1 alleles in idiopathic membranous nephropathy. $N$ Engl J Med. 2011;364(7):616-26.

8. Ghafari A, Etemadi J, Ardalan MR. Renal transplantation in patients with lupus nephritis: a single-center experience. Transplant Proc. 2008;40(1):143-4.

9. Ardalan MR, Shoja MM. Multiple myeloma presented as acute interstitial nephritis and rheumatoid arthritis-like polyarthritis. Am J Hematol. 2007;82(4):309-13.

10. Spitzer TR, Sykes M, Tolkoff-Rubin N, Kawai T, McAfee SL, Dey BR, et al. Long-term follow-up of recipients of combined human leukocyte antigen-matched bone marrow and kidney transplantation for multiple myeloma with end-stage renal disease. Transplantation. 2011;91(6):672-6.

11. Pham PT, Pham PC. Graft loss due to recurrent lupus nephritis in living-related kidney donation. Clin J Am Soc Nephrol. 2011;6(9):2296-9.

12. Fotouhi N, Ardalan M, Jabbarpour Bonyadi M, Abdolmohammadi R, Kamalifar A, Nasri H, et al. R229Q polymorphism of NPHS2 gene in patients with late-onset steroid-resistance nephrotic syndrome: a preliminary study. Iran J Kidney Dis. 2013;7(5):399-403.

13. Molnar MZ, Mehrotra R, Duong U, Bunnapradist S, Lukowsky LR, Krishnan M, et al. Dialysis modality and outcomes in kidney transplant recipients. Clin J Am Soc Nephrol. 2012;7(2):332-41.

14. Noshad H, Sadreddini S, Nezami N, Salekzamani Y, Ardalan MR. Comparison of outcome and quality of life: haemodialysis versus peritoneal dialysis patients. Singapore Med J. 2009;50(2):185-92.

15. Somi MH, Keivani H, Ardalan MR, Farhang S, Pouri AA. Hepatitis $C$ virus genotypes in patients with end-stage renal disease in East Azerbaijan, Iran. Saudi J Kidney Dis Transpl. 2008;19(3):461-5.

16. Ardalan MR, Shoja MM, Ghabili K, Taheri S, Shakeri A, Etemadi J, et al. Fulminant acute pancreatitis in a patient with familial mediterranean fever on CAPD: what caused the pancreatitis? Perit Dial Int. 2009;29(6):676-8.

17. Ghafari A, Ardalan MR. Renal transplantation in elderly recipients: a single-center experience. Transplant Proc. 2008; 40(1):238-9.

18. Ardalan MR, Tarzamani MK, Mortaazavi M, Bahloli A. Relation between resistive index and serum creatinine level in first month after renal transplantation. Transplant Proc. 2003;35(7):2628-9.

19. Ardalan MR, Tarzamani MK, Shoja MM. A correlation between direct and indirect Doppler ultrasonographic measures in transplant renal artery stenosis. Transplant Proc. 2007;39(5):1436-8.

20. Godwin JG, Ge X, Stephan K, Jurisch A, Tullius SG, Iacomini J. Identification of a microRNA signature of renal ischemia reperfusion injury. Proc Natl Acad Sci U S A. 2010;107(32):14339-44.

21. Zununi Vahed S, Nikasa P, Ardalan M. Klotho and renal fibrosis. Nephrourol Mon. 2013;5(5):946-8.

22. Zununi V. S., Samadi N. Diagnosis of interstitial fibrosis and 
tubular atrophy in kidney allograft: implementation of microRNAs. Iran J Kidney Dis. 2014;8:4-12.

23. Archdeacon P, Chan M, Neuland C, Velidedeoglu E, Meyer J, Tracy L, et al. Summary of FDA antibody-mediated rejection workshop. Am J Transplant. 2011;11(5):896-906.

24. Kimball PM, Baker MA, Wagner MB, King A. Surveillance of alloantibodies after transplantation identifies the risk of chronic rejection. Kidney Int. 2011;79(10):1131-7.

25. Loupy A, Lefaucheur C, Vernerey D, Prugger C, Duong van Huyen JP, Mooney N, et al. Complement-binding anti-HLA antibodies and kidney-allograft survival. N EnglJ Med.2013;369(13):1215-26.

26. Burns JM, Cornell LD, Perry DK, Pollinger HS, Gloor JM, Kremers WK, et al. Alloantibody levels and acute humoral rejection early after positive crossmatch kidney transplantation. Am J Transplant. 2008;8(12):2684-94.

27. Riethmuller S, Ferrari-Lacraz S, Muller MK, Raptis DA, Hadaya K, Rusi B, et al. Donor-specific antibody levels and three generations of crossmatches to predict antibody-mediated rejection in kidney transplantation. Transplantation. 2010;90(2):160-7.

28. Alachkar N, Lonze BE, Zachary AA, Holechek MJ, Schillinger K, Cameron AM, et al. Infusion of high-dose intravenous immunoglobulin fails to lower the strength of human leukocyte antigen antibodies in highly sensitized patients. Transplantation. 2012;94(2):165-71.

29. Niederhaus SV, Muth B, Lorentzen DF, Wai P, Pirsch JD, Samaniego-Picota $\mathrm{M}$, et al. Luminex-based desensitization protocols: the University of Wisconsin initial experience. Transplantation. 2011;92(1):12-7.

30. Djamali A, Muth BL, Ellis TM, Mohamed M, Fernandez LA, Miller $\mathrm{KM}$, et al. Increased C4d in post-reperfusion biopsies and increased donor specific antibodies at one-week post transplant are risk factors for acute rejection in mild to moderately sensitized kidney transplant recipients. Kidney Int. 2013;83(6):1185-92.

31. Sampaio MS, Cho YW, Qazi Y, Bunnapradist S, Hutchinson IV, Shah T. Posttransplant malignancies in solid organ adult recipients: an analysis of the U.S. National Transplant Database. Transplantation. 2012;94(10):990-8.

32. Einollahi B, Rostami Z, Nourbala MH, Lessan-Pezeshki M, Simforoosh N, Nemati E, et al. Incidence of malignancy after living kidney transplantation: a multicenter study from iran. J Cancer. 2012;3:246-56.

33. Einollahi B, Lessan-Pezeshki M, Nourbala MH, Simforoosh N, Pourfarziani V, Nemati E, et al. Posttransplant lymphoproliferative disorders in kidney transplant recipients: an Iranian multicenter experience. Iran J Kidney Dis. 2008;2(4):227-33.

34. Einollahi B, Lessan-Pezeshki M, Nourbala MH, Simforoosh N Pourfarziani V, Nemati E, et al. Kaposi's sarcoma following living donor kidney transplantation: review of 7,939 recipients. Int Urol Nephrol. 2009;41(3):679-85.

35. Sharif A. Should metformin be our antiglycemic agent of choice post-transplantation? Am J Transplant. 2011;11(7):1376-81.

36. Nasri H, Baradaran A, Ardalan MR, Mardani S, Momeni A, Rafieian-Kopaei M. Bright renoprotective properties of metformin: beyond blood glucose regulatory effects. Iran J Kidney Dis. 2013;7(6):423-8.

37. Ardalan M. Urinary tract infection associated with thrombotic microangiopathy. Nephrourol Mon. 2014;6(1).

38. Ardalan MR. Review of thrombotic microangiopathy (TMA), and post-renal transplant TMA. Saudi J Kidney Dis Transpl. 2006;17(2):235-44.

39. Ardalan MR, Shoja MM, Tubbs RS, Etemadi J, Esmaili H, Khosroshahi HT. Thrombotic microangiopathy in the early post-renal transplant period. Ren Fail. 2008;30(2):199-203.

40. Etemadi J, Mortazavi-Khosrowshahi M, Ardalan MR, Esmaili H, Javadrashid R, Shoja MM. Brown tumor of hyperparathyroidism masquerading as central giant cell granuloma in a renal transplant recipient: a case report. Transplant Proc. 2009;41(7):2920-2.

41. Nickeleit V, True K, Detwiler R, Kozlowski T, Singh H. Risk assessment for polyomavirus nephropathy using urine cytology and the detection of decoy cells: cheap and efficient. Transplantation. 2012;94(7):e42-4.

42. Trydzenskaya H, Juerchott K, Lachmann N, Kotsch K, Kunert K,
Weist B, et al. The genetic predisposition of natural killer cell to BK virus-associated nephropathy in renal transplant patients. Kidney Int. 2013;84(2):359-65.

43. Ardalan MR, Shoja MM, Tubbs RS, Ghabili K. Transplant renal artery stenosis associated with acute cytomegalovirus infection: resolution following ganciclovir administration. Ren Fail. 2009;31(10):982-4.

44. Ardalan M, Shoja MM. Cytomegalovirus-induced adrenal insufficiency in a renal transplant recipient. Transplant Proc. 2009;41(7):2915-6.

45. Ardalan M. Rare presentations of cytomegalovirus infection in renal allograft recipients. Nephrourol Mon. 2012;4(2):431-6.

46. Kotton CN. CMV: Prevention, Diagnosis and Therapy. Am J Transplant. 2013;13 Suppl 3:24-40.

47. Atabani SF, Smith C, Atkinson C, Aldridge RW, Rodriguez-Peralvarez $\mathrm{M}$, Rolando $\mathrm{N}$, et al. Cytomegalovirus replication kinetics in solid organ transplant recipients managed by preemptive therapy. Am J Transplant. 2012;12(9):2457-64.

48. Ardalan MR, Shoja MM, Tubbs RS, Jayne D. Parvovirus B19 microepidemic in renal transplant recipients with thrombotic microangiopathy and allograft vasculitis. Exp Clin Transplant. 2008;6(2):137-43.

49. Ardalan MR, Shoja MM, Tubbs RS, Esmaili H, Keyvani H. Postrenal transplant hemophagocytic lymphohistiocytosis and thrombotic microangiopathy associated with parvovirus b19 infection. Am JTransplant. 2008;8(6):1340-4.

50. Shoja MM, Ardalan MR, Etemadi J, Tubbs RS, Varshochi M. Renal allograft abscesses following transplant: case report and literature review. Exp Clin Transplant. 2007;5(2):720-3.

51. Ardalan MR, Ansarin K, Hejazi E, Nazemieh M, Safa J. Aspergillosis after renal transplantation. Saudi J Kidney Dis Transpl. 2005;16(3):330-3.

52. Ardalan MR, Shoja MM, Ghabili K. Concomitant pulmonary tuberculosis and tuberculous appendicitis in a recipient of a renal transplant: a case report. J Med Case Rep. 2011;5:191.

53. Ardalan M, Ghaffari A, Ghabili K, Shoja MM. Lepromatous leprosy in a kidney transplant recipient: a case report. Exp Clin Transplant. 2011;9(3):203-6.

54. Wadei H, Alangaden GJ, Sillix DH, El-Amm JM, Gruber SA, West MS et al. West Nile virus encephalitis: an emerging disease in renal transplant recipients. Clin Transplant. 2004;18(6):753-8.

55. Ardalan MR, Tubbs RS, Chinikar S, Shoja MM. Crimean-Congo haemorrhagic fever presenting as thrombotic microangiopathy and acute renal failure. Nephrol Dial Transplant. 2006;21(8):23047.

56. Souza WM, Bello G, Amarilla AA, Alfonso HL, Aquino VH, Figueiredo LT. Phylogeography and evolutionary history of rodent-borne hantaviruses. Infect Genet Evol. 2014;21:198-204.

57. Ardalan MR, Ghabili K, Pourabbas R, Shoja MM. A causative link between periodontal disease and glomerulonephritis: a preliminary study. Ther Clin Risk Manag. 2011;7:93-8.

58. Ardalan MR, Shoja MM. Rapidly progressive glomerulonephritis in a patient with brucellosis. Nephrol Dial Transplant. 2006;21(6):1743-4.

59. Bonyadi M, Esmaeili M, Jalali H, Somi MH, Ghaffari A, Rafeey M, et al. MEFV mutations in Iranian Azeri Turkish patients with familial Mediterranean fever. Clin Genet. 2009;76(5):477-80.

60. Ardalan M. Massive proteinuria and acute glomerulonephritis picture in a patient with Familial Mediterranean fever and E148Q mutation. Iranian J Kid Dis.;1(1).

61. Ardalan MR, Sadreddini S, Noshad H, Ebrahimi A, Molaeefard M, Somi MH, et al. Renal involvement in Behcet's disease. Saudi J Kidney Dis Transpl. 2009;20(4):618-22.

62. Ardalan MR, Shoja MM, Kiuru-Enari S. Amyloidosis-related nephrotic syndrome due to a G654A gelsolin mutation: the first report from the Middle East. Nephrol Dial Transplant. 2007;22(1):272-5.

63. Shoja MM, Ardalan MR, Tubbs RS, Kiuru-Enari S. Outcome of renal transplant in hereditary gelsolin amyloidosis. Am J Med Sci. 2009;337(5):370-2.

64. Ardalan M, Khodaie L, Nasri H. Herbs and Hazards; Admonishmen. Acid Neph J. 2014;1(1). 